Article

\title{
Smartphone Coupled with a Paper-Based Colorimetric Device for Sensitive and Portable Mercury Ion Sensing
}

\author{
M. Lutfi Firdaus ${ }^{1, * \mathbb{D}}$, Angga Aprian ${ }^{1}$, Nessi Meileza ${ }^{1}$, Marti Hitsmi ${ }^{1}$, Rina Elvia ${ }^{1}$, \\ Lena Rahmidar ${ }^{2}$ and Renat Khaydarov ${ }^{3}$ \\ 1 Graduate School of Science Education, University of Bengkulu, Bengkulu 38371, Indonesia; \\ anggaaprian13@gmail.com (A.A.); nessimeileza23@gmail.com (N.M.); martihitsmi31@gmail.com (M.H.); \\ relvia@unib.ac.id (R.E.) \\ 2 Material Science Research Group, Universitas BSI, Bandung 40291, Indonesia; lenarahmidar@gmail.com \\ 3 Institute of Nuclear Physics, Uzbek Academy of Sciences, Tashkent 100214, Uzbekistan; renat2@gmail.com \\ * Correspondence: lutfi@unib.ac.id; Tel.: +62-822-1721-6770
}

Received: 8 April 2019; Accepted: 13 May 2019; Published: 17 May 2019

check for updates

\begin{abstract}
The rapid development of information and communication technology provides an opportunity for scientists to develop a quantitative analytical method that is built on a mobile gadget as a detector. In this paper, we report a low-cost, simple and portable analytical method for mercury ion quantification based on digital image colorimetry coupled with a smartphone application. A small amount of silver nanoparticles (AgNPs) was used as a colorimetric agent that is selective only to mercury ions. The yellowish brown color of AgNPs instantly changed to colorless after the addition of mercury ions due to a redox reaction. To increase the portability, we attached the AgNPs onto a medium to create a paper-based analytical device. The final data processing of the colorimetric analysis was conducted using an android application available on the Google Play Store, called "Mercury Detector". The proposed method has good sensitivity, with a detection limit of $0.86 \mathrm{ppb}$, which is comparable to those of bulk and more expensive instruments. This allows for the detection of mercury ions as low as $2 \mathrm{ppb}(10 \mathrm{nM})$, which is also the maximum contaminant level permitted in drinking water by the US Environmental Protection Agency. The proposed method was applied to real samples that provide satisfactory results on accuracy $(2.4 \%)$ and precision $(2.5 \%)$.
\end{abstract}

Keywords: mercury; toxic metal; silver nanoparticles; colorimetry; spectrophotometry; digital image; smartphone application; paper-based analytical device

\section{Introduction}

Modern industrial developments often pay minimal attention to environmental sustainability. Mercury has been used extensively in various industries such as gold and coal mining as well as in electrical equipment, batteries, semiconductors and medical appliances [1-5]. Mercury compounds are also naturally emitted into the atmosphere from volcanoes, forest fires, the weathering of rocks and soils [6]. Although it benefits various industries, mercury and its derivatives are harmful to ecosystems and to humans. Elemental and organic mercury is toxic to the peripheral and central nervous systems. The exposure of mercury vapor can produce adverse effects on the neural, digestive and immune systems [3]. Methylmercury is the most toxic derivate amongst the mercury compounds that develop from inorganic mercury through the activity of microorganisms living in aquatic systems including rivers, lakes, wetlands, sediments, soils and the ocean. The higher toxicity of methylmercury compared with inorganic mercury is the result of its lipophilic nature. It tends to bioaccumulate within the living cell and subsequently undergoes bioaccumulation throughout the food chain [7]. Therefore, mercury 
in the natural environment is an important chemical that needs to be monitored continuously due to its extremely toxic nature.

Recently, digital image-based colorimetry is receiving more attention as an alternative to the conventional methods, owing to its green, low-cost, portable and simple analytical procedure to analyze chemical compounds including metals [8-11], anions [12,13], organics [14,15], biochemical compounds [16,17] and medical applications [18-20]. The dynamic range of the digital image represented by red-green-blue or RGB color space (i.e., from 0 to 255), is much broader than conventional colorimetry or spectrophotometry methods (i.e., from 0 to 2.0 absorbance) providing the opportunity to improve the sensitivity of detection $[8,18]$. The main requirement of quantitative analysis using the colorimetry method is that the target analyte must be colored. Generally, the analyst uses organic ligands to make the colorless metal of interest colorful. However, organic ligands are toxic and less selective to specific metal targets. Recently, many researchers have developed noble metal nanoparticles as color probes to detect mercury ions [21-24]. Gold and silver nanoparticles have several advantages over organic ligands to make colorless metals colorful, such as better sensitivity, greater selectivity to a specific metal's target and lower toxicity. Therefore, this new kind of colorimetry using digital imaging coupled with noble metal nanoparticles is becoming popular in the detection of mercury ions. However, the limit of detection (LOD) is at the sub-ppm range [25,26], comparable to those of conventional colorimetry and spectrophotometry methods, and is still too high to detect mercury contamination in drinking water. Therefore, it is crucial to improve the LOD of the previously proposed colorimetry methods. Here, we report the first quantitative method for the detection of mercury ions at the ppb level using silver nanoparticles as a probe, coupled with image-based colorimetric sensing. In addition, we built a paper-based analytical device (PAD) and a smartphone application for better portability.

\section{Materials and Methods}

\subsection{Chemicals and Instruments}

All chemicals used were of analytical grade or of the highest purity available. Silver nitrate, ascorbic acid, trisodium citrate, salts of cations for selectivity tests and other chemicals were supplied by Merck Ltd. (Darmstadt, Germany). All glassware was washed with detergent (5\%), $4 \mathrm{M} \mathrm{HCl}$ and deionized water before use. River water samples were filtered through a $2.5 \mu \mathrm{m}$ Whatman filter paper (GE Healthcare, UK). Absorption spectra of the synthesized silver nanoparticles (AgNPs) were measured using a UV-visible Spectrophotometer (B-One, Messgerate). As a reference method, mercury ion analysis was conducted using ICP-OES (Varian 725-ES Agilent Inc., Palo Alto, CA, USA). A smartphone camera (Redmi Note 3 Pro, Xiaomi, Beijing, China) with a 16 MP sensor, f/2.0 aperture, phase detection focusing and dual-LED (Light Emitting Diode) flash was used to record pictures as digital images.

\subsection{Silver Nanoparticles (AgNPs) Preparation}

AgNPs were synthesized from silver nitrate $\left(\mathrm{AgNO}_{3}\right)$ with ascorbic acid as a reductant. Trisodium citrate was used as a stabilizing agent to prevent aggregation of the formed AgNPs. Typically, $80 \mu \mathrm{L}$ of $0.1 \mathrm{M}$ aqueous $\mathrm{AgNO}_{3}$ was added into $8 \mathrm{~mL}$ of aqueous solution containing ascorbic acid $\left(6 \times 10^{-4} \mathrm{M}\right)$ and trisodium citrate $\left(3 \times 10^{-3} \mathrm{M}\right)$ under constant stirring at $30^{\circ} \mathrm{C}$ on a hotplate. The procedure was conducted at pH 7.0, modified from Qin et al. [27]. The colloid of AgNPs was formed after $15 \mathrm{~min}$ and is characterized by the appearance of a yellowish brown color from the initial colorless solution. Further characterization of the AgNPs was conducted using the spectrophotometer.

\subsection{Image Acquisition and Paper-Based Analytical Device (PAD) Preparation}

Digital images of the sample in cuvettes were taken by a smartphone in a custom-made mini photo studio, while those of the PAD were taken in a custom-made photo box. The PAD was printed on a Whatman filter paper (GE Healthcare, Little Chalfont, UK), using a modified inkjet ip2770 printer 
(Canon, Tokyo, Japan) with hydrophobic ink and permanent-ink markers. The post-processing of the digital image was initially done using a personal computer with software such as Photoshop (Adobe Inc., San Jose, CA, USA) for cropping and adjustment, MATLAB (MathWorks) for RGB color value extraction and Android Studio (Google Inc., Mountain View, CA, USA) for building the smartphone application. More detailed procedures have been published elsewhere [8,26,28-30].

\subsection{Quantification of the Digital Image}

To validate the code of the smartphone application, we used manual image processing procedures described as follows [8]. In brief, the digital image from the smartphone camera was transferred to the computer and processed with Adobe Photoshop software. In this case, a digital image from the smartphone camera serves as a spectrophotometer analyzing the light passing through the colloid of the AgNPs. The average RGB color values were extracted from the image using MATLAB software. The raw plot of the RGB color values against the concentration of the standards, produces a hyperbolic trend. To obtain a linear plot for further usage, the initial RGB color values were converted to logarithmic scale following the Lambert-Beer law derivation formula as follows [8]:

$$
I_{R}=\log \frac{R_{0}}{R_{s}} ; I_{G}=\log \frac{G_{0}}{G_{s}} ; I_{B}=\log \frac{B_{0}}{B_{s}} .
$$

$\mathrm{I}_{\mathrm{R}}, \mathrm{I}_{\mathrm{G}}$ and $\mathrm{I}_{\mathrm{B}}$ are the (color) intensity or absorbance for red, green and blue, respectively. The terms $(\mathrm{RGB})_{0}$ and (RGB)s are the RGB color values of the blank and the sample, respectively. It should be pointed out that here, the term 'intensity' refers to the number of $R, G$ and $B$ color values of the digital image, and thus is different from that used in UV-visible spectrophotometry. The logarithmic conversion of RGB color values is directly proportional to the mercury ion concentration, so it can be used for the quantification of mercury ions in the samples.

\subsection{Construction of the Smartphone Application}

Android Studio software was used to build the app for in situ digital image cropping, adjustment, color value extraction and data processing. Directly after pouring the samples solution into the colloid of the AgNPs or the PAD, the digital image was captured as a photograph and processed by the android application. Thus, the concentration of mercury ions in the photographed sample can be identified instantly by the smartphone. To minimize any error from the camera and external sources, the samples were always photographed together with the standards in one file. Thus, errors from external sources were minimized. We also used an additional application (Camera FV-5), to manually control the camera setting with ISO 200, aperture $\mathrm{f} / 2.0$, focus, white balance and exposure. The examples of the smartphone application interface and android studio coding are shown in the Supplementary Materials (Figure S1). The application was published and can be downloaded from the Google Play Store under the name "Mercury Detector."

\section{Results and Discussion}

\subsection{Silver Nanoparticles as a Colorimetric Agent}

The synthesized AgNPs have a yellowish brown color with the highest absorbance obtained at $420 \mathrm{~nm}$ wavelength $\left(\lambda_{\max }\right)$. This result was in accordance with previous reports [26-28]. The AgNPs were stable for 30 days as shown by the color and the uniform peak absorbance (Figure S2). However, after 45 days, the aggregation of nanoparticles started to occur, and the peak absorbance also decreased. The aggregation of the AgNPs that occurs after a longer period of storage (more than 30 days) is probably due to electromagnetic interactions among the silver nanoparticles which induce the agglomeration of AgNPs to a larger size. This phenomenon eventually changes the yellowish brown color of AgNPs to dark brown and then it becomes colorless, followed by the formation of the suspended particles at the bottom of the container. The mechanism for mercury colorimetric detection using silver nanoparticles 
as a probe is reduction-oxidation. The oxidation of $\mathrm{Ag}(0)$ to $\mathrm{Ag}(\mathrm{I})$ by $\mathrm{Hg}(\mathrm{II})$ changes the color of the AgNPs to colorless. This redox reaction generates the change in the nanoparticles' size known as the Mie blue shift of the AgNPs' absorption band [26].

By using the fresh AgNPs, the selectivity experiment was conducted on various cations that could interfere with the accuracy and precision of the proposed method. There is no color change of AgNPs after adding $60 \mathrm{ppm}$ of aluminum, calcium, chromium, cobalt, copper, iron, lead, magnesium, manganese, nickel, potassium, sodium and zinc. However, when $\mathrm{Hg}$ was added to AgNPs, the peak absorbance at $420 \mathrm{~nm}$ disappeared and the mixture became colorless within seconds. This proved that the proposed method is selective to mercury ions only (Figure 1).

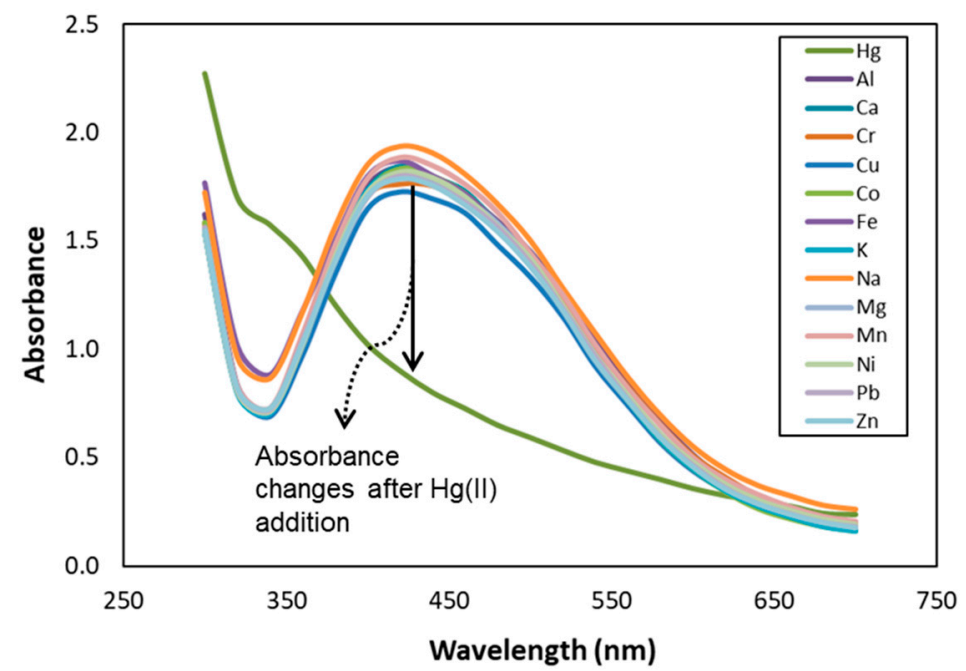

Figure 1. Change in absorbance of the silver nanoparticles' (AgNPs) colloid in the presence of $60 \mathrm{ppm}$ $\mathrm{Hg}(\mathrm{II})$ and other metal ions.

\subsection{Improving the Sensitivity and Portability of Digital Image-Based Colorimetry}

Most of the colorimetry methods for mercury quantification can only achieve a detection limit (LOD) comparable to that of a visible spectrophotometer, which is in the sub-ppm range, with visible color changes starting from 20 ppm or above [26,28-30]. However, the threshold of mercury in drinking water allowed by the US Environmental Protection Agency (EPA) is 2 ppb [31,32], which is two orders of magnitude lower than the detection limit achieved by most colorimetry and spectrophotometry methods. To overcome this shortcoming, in this report we improved the detection limit by using a custom-made mini photo studio to control the light as shown in Figure 2.

Aside from using the custom-made photo studio, cuvettes replaced vial bottles that were used in previous methods as cuvettes have a flat surface. The flat form of the container's surface is crucial in achieving accurate and precise results with digital image-based colorimetry. By using flat-surfaced cuvettes as sample containers, coupled with white LED lamps from photo studio lighting, we could easily distinguish mercury concentration at the ppb level as shown in Figure 2 and Table 1 . The results of ppm-level plots are shown in Figure S3. The intensity of the blue color increases linearly along with the increasing mercury concentration from 1 to $4 \mathrm{ppb}$ (Table 1 and Figure 3). Blue is the complementary color of the yellowish brown color of AgNPs. Therefore, blue will have the best linearity and highest slope. As a consequence, since red and green are not the complementary colors of AgNPs, they will have poor linearity and slope. Thus, we only used blue intensity for further calculation for our research. Using the optimized method, we were able to achieve a lower detection limit $-0.86 \mathrm{ppb}-$ calculated from three times the standard deviation $(\sigma)$ of 10 replicates of blank measurements, divided by the slope of the calibration curve at the ppb level ( $3 \sigma$ of the blank/slope). 
(a)
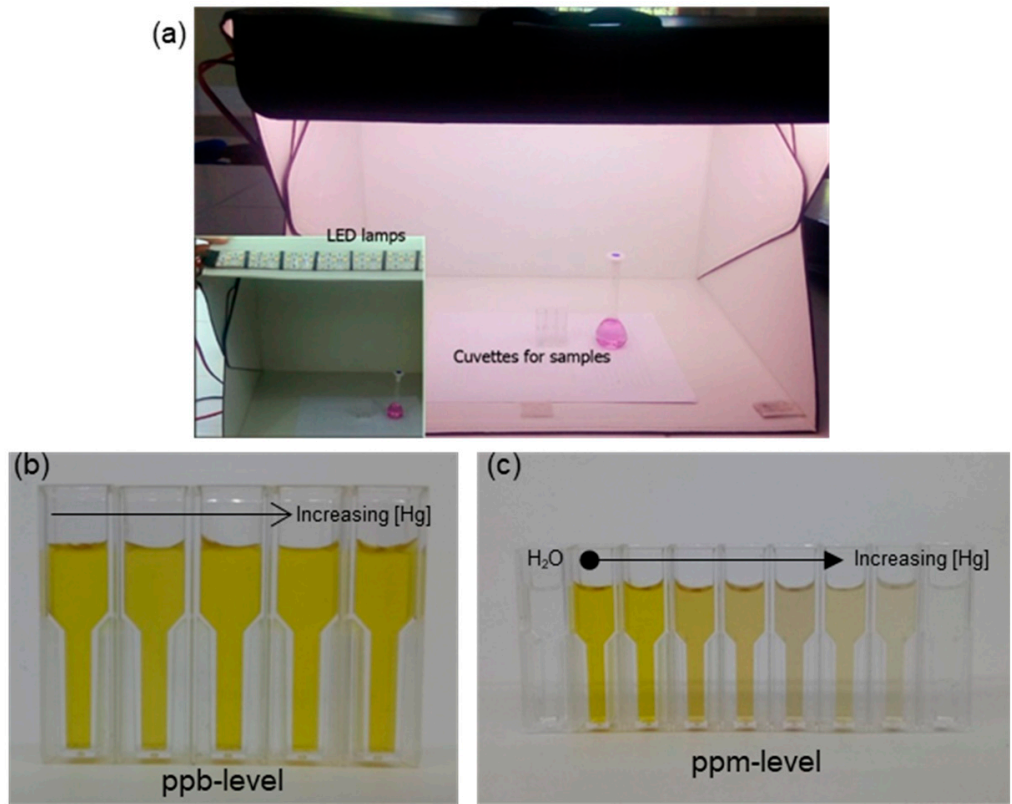

Figure 2. (a) Custom photo studio with 12 Volt LED lamps for appropriate lighting; (b) the result of the digital image at ppb-level mercury standards from 0 to $4 \mathrm{ppb}$; (c) the color change at the ppm level of mercury ion concentration from 0 to $150 \mathrm{ppm}$. The volume of the sample in each cuvette was $1 \mathrm{~mL}$.

Table 1. RGB color value and intensity of the mercury calibration curve at the ppb level.

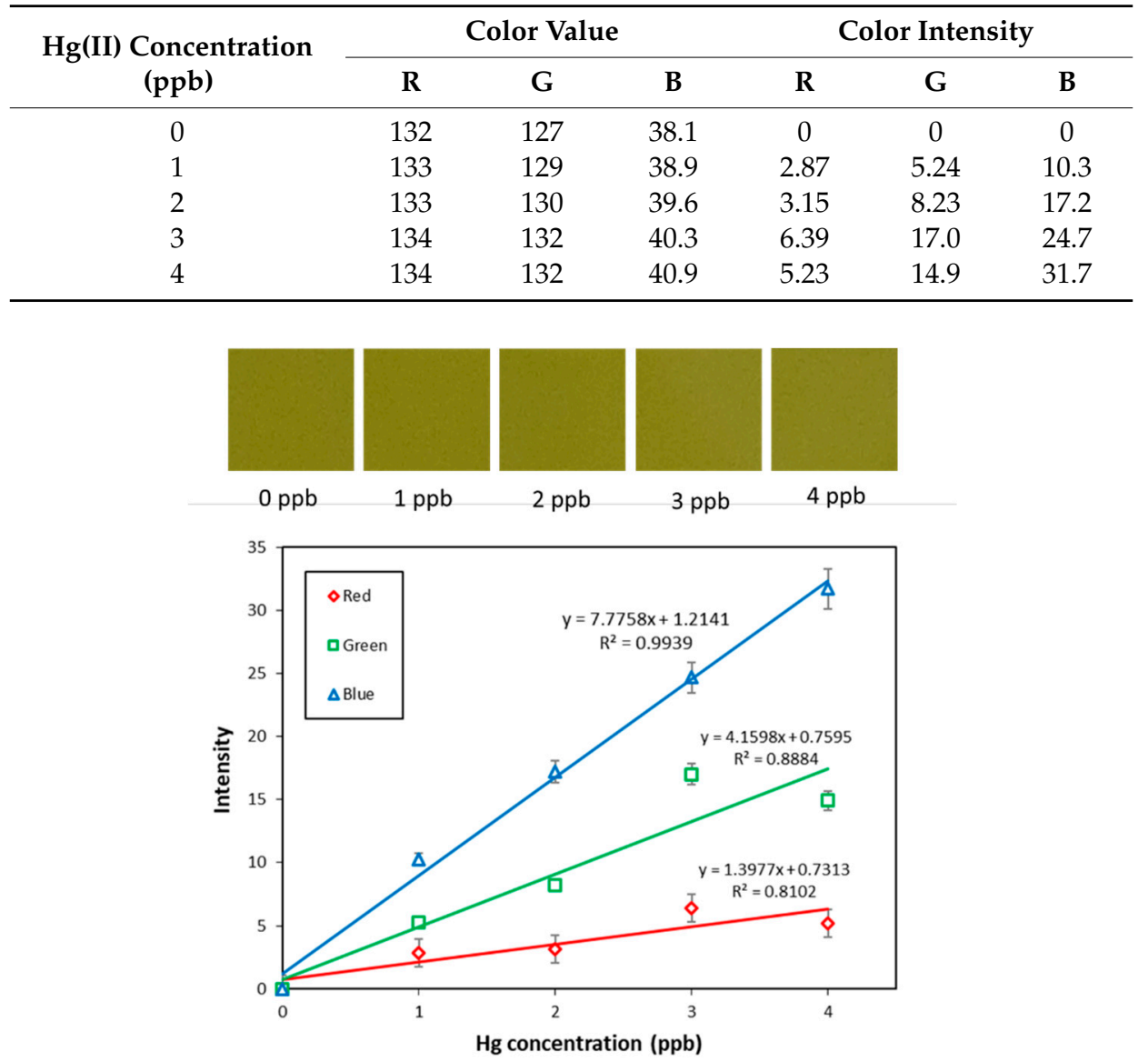

Figure 3. The cropped digital image of standard solutions containing 1 to $4 \mathrm{ppb}$ mercury ions, and the corresponding calibration curve with blue color as the complementary color of the yellowish brown color of AgNPs that gives the highest slope. Error bars were calculated from three replicates. 
As a means of increasing portability, we applied the method to the paper-based analytical device (PAD) $[33,34]$. The PAD was built on a Whatman filter paper that has a good porosity for the movement of the sample solution. Hydrophobic ink was used to fortify the fluid and keep it in the reaction channel. A permanent-ink marker was also used to make the channel constraint line of the PAD better. After filter paper for the PAD was heated at $150{ }^{\circ} \mathrm{C}$ for $5 \mathrm{~min}$ in an oven, the ink swelled and penetrated the bottom of the paper, which aids in preventing the solution from leaking from the backside. The digital image file was then taken in a custom photo box using a smartphone. The actual photograph of the PAD, with a diameter of $3 \mathrm{~cm}$, is shown in Figure 4 . The results of the PAD digital image processing were in accordance with those of cuvette digital image processing.

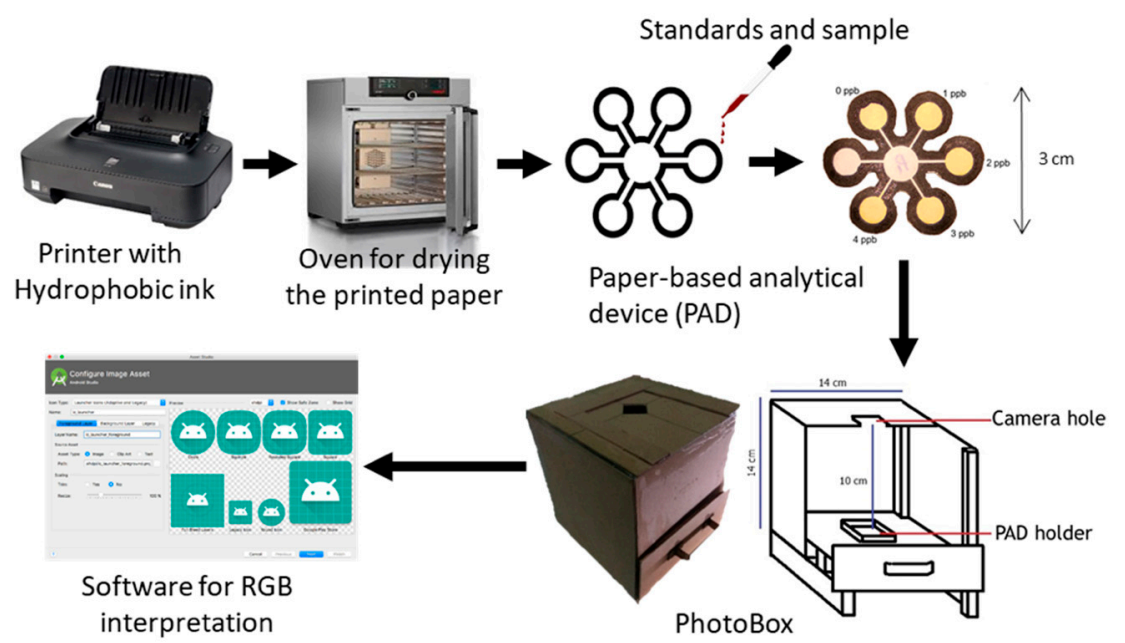

Figure 4. Schematic of the paper-based analytical device (PAD) preparation and digital image acquisition for mercury ion determination. As with the colorimetric sensor, silver nanoparticles were embedded on the PAD before sample addition. Each piece of PAD paper contains standards and a sample.

\subsection{Recovery Experiments}

To validate the proposed method, we conducted recovery experiments from real samples, which have their own sample's matrix, using the standard addition method and spiking the sample. River water close to the effluent point of artisanal and small-scale gold mining in Bengkulu province was chosen as the target sample. For the digital image-based colorimetry method, the mercury concentration was determined from Blue color intensity by using the Lambert-Beer equation (Figure S4), following the method in our previously published paper [8]. The results are shown in Table 2, using both the liquid approach and the PAD, with ICP-OES as a reference method for the accuracy test. The accuracy, calculated as the percent error of the proposed digital image-based colorimetry method, was less than $2.4 \%$. The precision of the proposed method, calculated as the percent relative standard deviation (RSD) from three replicate analyses, was better than $2.5 \%$. Therefore, the accuracy and precision were satisfactory.

Table 2. Recovery experiments of spiked river water samples $(n=3)$.

\begin{tabular}{|c|c|c|c|}
\hline \multirow{2}{*}{ Added Hg(II) (ppb) } & \multicolumn{2}{|c|}{ Digital Image-Based Colorimetry } & \multirow{2}{*}{$\begin{array}{c}\text { ICP-OES } \\
(p p b)\end{array}$} \\
\hline & Found (ppb) & Recovery (\%) & \\
\hline 0 & $81.7 \pm 2.5$ & - & 83.2 \\
\hline 40 & $123 \pm 3$ & 101 & 126 \\
\hline 80 & $160 \pm 4$ & 98.9 & 161 \\
\hline
\end{tabular}

The high content of mercury ions in river water at the gold mining area (i.e., $81.7 \mathrm{ppb}$ ) shows that the use of mercury for gold extraction contaminated the water body. The release of mercury into river 
water will pollute freshwater biota that in turn will endanger humans themselves, as a result of mercury bioaccumulation in fish. A more detailed discussion on this matter will be published elsewhere.

\section{Conclusions}

In the current digital era, one of the most affordable and straightforward quantitative methods is to monitor the color change of an analyte of interest using a ubiquitous smartphone. Modern smartphones mostly have a good quality camera with high resolution. In our research, we used a built-in smartphone camera and a smartphone application for processing the primary color input, as red-green-blue (RGB) channels, in order to analyze mercury ion concentration. Decent ambiance lighting is crucial to obtain accurate, precise and sensitive results. In addition, the flat surface of cuvettes used as the sample containers gave better results compared to the round-surfaced sample containers (e.g., vial bottles). By combining the digital image-based colorimetry with paper-based analytical devices and using a smartphone as a detector, we achieved better portability and sensitivity with good accuracy and precision. The proposed method assures a simple, low-cost, green and portable analytical method for mercury ion quantification that can be used in a remote area with limited resources.

Supplementary Materials: The following are available online at http://www.mdpi.com/2227-9040/7/2/25/s1, Figure S1: Examples of application appearance in Google Play Store and its corresponding android studio coding, Figure S2: Color stability of the synthesized AgNPs through time. The synthesized AgNPs were stable for 30 days and started to aggregated at days 45 and on, as shown from the decrease of peak absorbance, Figure S3: The plot of absorbance from spectrophotometer (upper) and its corresponding Blue intensity from digital image (below) of ppm-level mercury addition into AgNPs. Decreasing and gradual broadening on the absorbance of the surface plasmon resonance band, known as Mie blue shift, were noticed during successive addition of mercury ions into silver nanoparticles along with a blue shift from $420 \mathrm{~nm}$ for initial AgNPs to $360 \mathrm{~nm}$ upon addition of mercury ions. At high concentrations (ppm-level), analysis can be carried out both by spectrophotometry and by the digital image colorimetry as shown on the calibration curve below. At low concentration (ppb-level); however, analysis of mercury ions using spectrophotometry is impossible due to the visually similar color of the samples that produce very poor calibration curve on absorbance. Therefore, mercury at ppb-level was detected using digital image-based colorimetry, Figure S4: The actual photograph of PAD-based colorimetry together with its RGB value and Lambert-Beer logarithmic converted RGB intensity. The RGB color value was extracted from the digital image containing ppb-level standards (1-4 ppb). The other two chambers were used for samples. Coresponding calibration curve for this ppb-level mercury standards is also shown.

Author Contributions: This paper was prepared through the contributions of all authors. M.L.F. designed and performed the experiment, wrote the initial manuscript and secured the research funding. A.A., N.M. and M.H. performed the experiment. R.E., L.R. and R.K. contributed to the final manuscript preparation.

Funding: This research was funded by the Indonesian Ministry of Research, Technology and Higher Education, grant numbers 053/SP2H/LT/DRPM/IV/2019 and PKM-PIMNAS 2018.

Acknowledgments: The authors acknowledge Dita Retnowati for developing the first version of the smartphone application and Hendry Nordan for the river water sampling and treatment.

Conflicts of Interest: The authors declare no conflict of interest. The funders had no role in the design of the study; in the collection, analyses, or interpretation of data; in the writing of the manuscript, or in the decision to publish the results.

\section{References}

1. Castilhos, Z.C.; Rodrigues-Filho, S.; Rodrigues, A.P.C.; Villas-Bôas, R.C.; Siegel, S.; Veiga, M.M.; Beinhoff, C. Mercury contamination in fish from gold mining areas in Indonesia and human health risk assessment. Sci. Total Environ. 2006, 368, 320-325. [CrossRef] [PubMed]

2. Tomiyasu, T.; Kono, Y.; Kodamatani, H.; Hidayati, N.; Rahajoe, J.S. The distribution of mercury around the small-scale gold mining area along the Cikaniki river, Bogor, Indonesia. Environ. Res. 2013, 125, 12-19. [CrossRef] [PubMed]

3. Jarup, L. Hazards of heavy metal contamination. Br. Med. Bull. 2003, 68, 167-182. [CrossRef]

4. Clarkson, T.W.; Magos, L.; Myers, G.J. The Toxicology of Mercury-Current Exposures and Clinical Manifestations. N. Engl. J. Med. 2003, 349, 1731-1737. [CrossRef] [PubMed] 
5. Khaydarov, R.R.; Khaydarov, R.A.; Gapurova, O.; Garipov, I.; Firdaus, M.L. Silver Nanoparticles as a Biocide for Water Treatment Applications. In Advanced Research in Nanosciences for Water Technology; Springer: Berlin, Germany, 2019; pp. 407-419.

6. El-Safty, S.A.; Shenashen, M.A.; El-Safty, S.A. Mercury-ion optical sensors. TrAC-Trends Anal. Chem. 2012, 38, 98-115. [CrossRef]

7. Hong, Y.; Kim, Y.; Lee, K. Methylmercury Exposure and Health Effects. J. Prev. Med. Public Health 2012, 45, 353-363. [CrossRef]

8. Firdaus, M.L.; Alwi, W.; Trinoveldi, F.; Rahayu, I.; Rahmidar, L.; Warsito, K. Determination of Chromium and Iron Using Digital Image-based Colorimetry. Procedia Environ. Sci. 2014, 20, 298-304. [CrossRef]

9. Masawat, P.; Harfield, A.; Srihirun, N.; Namwong, A. Green Determination of Total Iron in Water by Digital Image Colorimetry. Anal. Lett. 2017, 50, 173-185. [CrossRef]

10. Puchum, S.; Meelapsom, R.; Muniandy, S.S. Use of unmodified silver nanoparticles (AgNPs) as colorimetric $\mathrm{Hg}$ (II) sensor: A new approach to sensitive and high sample throughput determination of $\mathrm{Hg}$ (II) under high influence of ionic suppression. Int. J. Environ. Anal. Chem. 2019, 99, 1-18. [CrossRef]

11. Salcedo, A.R.M.; Sevilla, F.B. Colorimetric determination of mercury vapor using smartphone camera-based imaging. Instrum. Sci. Technol. 2018, 46, 450-462. [CrossRef]

12. Choodum, A.; Boonsamran, P.; Nicdaeid, N.; Wongniramaikul, W. On-site semi-quantitative analysis for ammonium nitrate detection using digital image colourimetry. Sci. Justice 2015, 55, 437-445. [CrossRef] [PubMed]

13. David, T.; Grandivoriana, N.A.; Fidelis, N. Digital-Based Image Detection System in Simple Silver Nanoparticles-based Cyanide Assays. Res. J. Chem. Environ. 2018, 22, 10-14.

14. Choodum, A.; Parabun, K.; Klawach, N.; Daeid, N.N.; Kanatharana, P.; Wongniramaikul, W. Real time quantitative colourimetric test for methamphetamine detection using digital and mobile phone technology. Forensic Sci. Int. 2014, 235, 8-13. [CrossRef] [PubMed]

15. Wongniramaikul, W.; Limsakul, W.; Choodum, A. A biodegradable colorimetric film for rapid low-cost field determination of formaldehyde contamination by digital image colorimetry. Food Chem. 2018, 249, 154-161. [CrossRef]

16. Tambaru, D.; Rupilu, R.H.; Nitti, F.; Gauru, I.; Suwari. Development of Paper-Based Sensor Coupled with Smartphone Detector for Simple Creatinine Determination. In AIP Conference Proceedings; AIP Publishing: College Park, MD, USA, 2017; p. 0200951.

17. Priye, A.; Ball, C.S.; Meagher, R.J. Colorimetric-Luminance Readout for Quantitative Analysis of Fluorescence Signals with a Smartphone CMOS Sensor. Anal. Chem. 2018, 90, 12385-12389. [CrossRef]

18. Fatoni, A.; Numnuam, A.; Kanatharana, P.; Limbut, W.; Thammakhet, C.; Thavarungkul, P. A highly stable oxygen-independent glucose biosensor based on a chitosan-albumin cryogel incorporated with carbon nanotubes and ferrocene. Sens. Actuators B Chem. 2013, 185, 725-734. [CrossRef]

19. Shen, L.; Hagen, J.A.; Papautsky, I. Point-of-care colorimetric detection with a smartphone. Lab Chi 2012, 12, 4240-4243. [CrossRef]

20. Priye, A.; Bird, S.W.; Light, Y.K.; Ball, C.S.; Negrete, O.A.; Meagher, R.J. A smartphone-based diagnostic platform for rapid detection of Zika, chikungunya, and dengue viruses. Sci. Rep. 2017, 7, 44778. [CrossRef] [PubMed]

21. Firdaus, M.L.; Puspita, M.; Alwi, W.; Ghufira; Nurhamidah; Elvia, R. Dyes Removal Using Activated Carbon from Palm Oil Waste with Digital Image Colorimetry Quantification. In AIP Conference Proceedings; AIP Publishing: College Park, MD, USA, 2017; p. 0200661.

22. Chansuvarn, W.; Tuntulani, T.; Imyim, A. Colorimetric detection of mercury(II) based on gold nanoparticles, fluorescent gold nanoclusters and other gold-based nanomaterials. TrAC-Trends Anal. Chem. 2015, 65, 83-96. [CrossRef]

23. Firdaus, M.; Andriana, S.; Alwi, W.; Swistoro, E.; Ruyani, A.; Sundaryono, A. Green synthesis of silver nanoparticles using Carica Papaya fruit extract under sunlight irradiation and their colorimetric detection of mercury ions. J. Phys. Conf. Ser. 2017, 817, 012029. [CrossRef]

24. Xu, H.; Wang, Y.; Huang, X.; Li, Y.; Zhang, H.; Zhong, X. $\mathrm{Hg}^{2+}$-mediated aggregation of gold nanoparticles for colorimetric screening of biothiols. Analyst 2012, 137, 924-931. [CrossRef] 
25. Maity, D.; Kumar, A.; Gunupuru, R.; Paul, P. Colloids and Surfaces A: Physicochemical and Engineering Aspects Colorimetric detection of mercury (II) in aqueous media with high selectivity using calixarene functionalized gold nanoparticles. Colloids Surf. A Physicochem. Eng. Asp. 2014, 455, 122-128. [CrossRef]

26. Firdaus, M.L.; Fitriani, I.; Wyantuti, S.; Hartati, Y.W.; Khaydarov, R.; McAlister, J.A.; Obata, H.; Gamo, T. Colorimetric Detection of Mercury (II) Ion in Aqueous Solution Using Silver Nanoparticles. Anal. Sci. 2017, 33, 831-837. [CrossRef]

27. Qin, Y.; Ji, X.; Jing, J.; Liu, H.; Wu, H.; Yang, W. Size control over spherical silver nanoparticles by ascorbic acid reduction. Colloids Surf. A Physicochem. Eng. Asp. 2010, 372, 172-176. [CrossRef]

28. Firdaus, M.L.; Krisnanto, N.; Alwi, W.; Muhammad, R.; Allan, M. Adsorption of Textile Dye by Activated Carbon Made from Rice Straw and Oil Palm Midrib. Aceh Int. J. Sci. Technol. 2017, 7, 1-7. [CrossRef]

29. Firdaus, M.L.; Susanti, E.; Ghufira; Alwi, W.; Swistoro, E. Isotherm, kinetics and thermodynamics of synthetic dyes adsorption onto activated charcoal made from oil palm midrib. Rasayan J. Chem. 2018, 11, 1532-1536. [CrossRef]

30. Firdaus, M.L.; Juwita, M.; Ibrahim, P.R.; Rakhmawaty, E.D.; Iman, R. Biosynthesis of Silver Nanoparticles using Jicama Extract and Its Application for Colorimetric Sensing of Mercury Ions. Res. J. Chem. Environ. 2018, 22, 1-3.

31. Gray, J.E.; Theodorakos, P.M.; Fey, D.L.; Krabbenhoft, D.P. Mercury concentrations and distribution in soil, water, mine waste leachates, and air in and around mercury mines in the Big Bend region, Texas, USA. Environ. Geochem. Health 2014, 37, 35-48. [CrossRef] [PubMed]

32. Du, J.; Jiang, L.; Shao, Q.; Liu, X.; Marks, R.S.; Ma, J.; Chen, X. Colorimetric detection of mercury ions based on plasmonic nanoparticles. Small 2013, 9, 1467-1481. [CrossRef] [PubMed]

33. Wang, X.; Zhang, Q.; Nam, C.; Hickner, M.; Mahoney, M.; Meyerhoff, M.E. Ionophore-based anion-selective optode printed on cellulose paper. Angew. Chem. Int. Ed. 2017, 56, 11826-11830. [CrossRef] [PubMed]

34. Tenda, K.; van Gerven, B.; Arts, R.; Hiruta, Y.; Merkx, M.; Citterio, D. Paper-Based Antibody Detection Devices Using Bioluminescent BRET-Switching Sensor Proteins. Angew. Chem. 2018, 130, 15595-15599. [CrossRef]

(C) 2019 by the authors. Licensee MDPI, Basel, Switzerland. This article is an open access article distributed under the terms and conditions of the Creative Commons Attribution (CC BY) license (http://creativecommons.org/licenses/by/4.0/). 